\title{
The Value of Collaborating with Undergraduate Students on an Interdisciplinary Project
}

\author{
Mackenzie Martin ${ }^{1}$, Jacquie Eales ${ }^{2}$, Janet Fast ${ }^{2}$, Carlos Florentino², Megan Strickfaden² \\ ${ }^{1}$ University of Oxford, Oxford, OX1 2JD, UK \\ 'University of Alberta, Edmonton, AB, Canada, TG6 2R3 \\ DOI: $10.47611 /$ jsr.v9i1.748
}

\section{$\underline{\text { ABSTRACT }}$}

In this reflective case study, an interdisciplinary collaboration among undergraduate students in a computing science course with a team of graduate and faculty researchers at the same Canadian university will be described. The paper will then outline the considerable benefits that resulted from this community service-learning approach. The paper will also delineate recommendations for others wishing to utilize a similar model in future so as to maximize the effectiveness of such partnerships.

\section{Introduction}

Over the last two decades, there has been increasing emphasis on fostering interdisciplinary research collaboration (Stokols, Harvey, Gress, Fuqua, \& Phillips, 2005). This is certainly the case in the context of research projects that aim to address 'wicked' societal problems (Beers, Boshuizen, Kirschener, \& Gijsellaers, 2006; Bruusgaard, Pinto, Swindle, \& Yoshino, 2010; Choi \& Pak, 2006; Fischer \& Otswald, 2005; Nissani, 1997). The belief is that "large and complex design projects cannot be accomplished by any single person and they often cut across different disciplines, requiring expertise in a whole range of areas" (Fischer \& Otswald, 2005, p. 3).

An example of such a wicked problem is how to care for and support Canada's aging population. Currently, family/friend carers provide a significant percentage of the care for older adults. It is estimated that approximately $46 \%$ of Canadians have provided care to a family member or friend with disabilities, aging needs, and health conditions (Sinha, 2013). Carers often experience a variety of health, social, economic, and employment consequences as a result of providing care (Keating, Fast, Lero, Lucas, \& Eales, 2014; Keating \& Eales, 2017; Turcotte, 2013). Assistive technologies ${ }^{1}$ have the potential to considerably reduce some of these costs.

AGE-WELL NCE Inc. is a pan-Canadian network that uses interdisciplinary and transdisciplinary approaches "to drive innovation and create technologies and services that benefit older adults and caregivers" (AGEWELL, n.d., para. 2). To achieve this goal, AGE-WELL brings together people from different academic disciplines and stakeholders from private, public, and non-governmental sectors. A team within the AGE-WELL network is looking to document the deficiencies of currently available assistive technologies and identify the existing technological gaps which, if filled, would better support carers. To meet these challenges, the team is comprised of members with a variety of disciplinary experience including in design, gerontology, human ecology, rehabilitation medicine, and

\footnotetext{
${ }^{1}$ An assistive technology can be either a product or service. Examples of assistive technology products include a swivel device for a car seat and a social media app that allows carers to communicate with each other. An example of an assistive technology service is a security monitoring system that responds to an older adult's signal for assistance and alerts his or her carer.
} 
economics. Further, the team includes members with different levels of academic achievement ranging from undergraduates to professors.

To discover the assistive technology deficiencies and technological gaps, the team sought to start by gathering information about the technological needs of carers, the assistive technologies currently available to them, and the details (e.g., price), design (e.g., weight), and carers' assessment of these technologies (e.g., ease of use). The team determined that a mobile app would be a useful way to amass this information. The team also determined that it needed the app to populate a database from the input with the goal of making the data available to product designers, producers, researchers, and others seeking information to inspire new assistive technologies that respond to carers' unmet needs or improve existing assistive technologies.

To design and develop the app, the team invited six senior undergraduate computing science students taking a "Software Process and Product Management" course under a Professor of Computing Science (also funded by AGEWELL) at the same institution to join the team as collaborators. The students had disciplinary knowledge and technical skills the original team lacked. The collaboration was mutually beneficial - it resulted in the creation of a functional app free of financial cost and contributed to the professional development of the students involved. This paper is a reflective case study of the project and the value of utilizing a community service-learning (CSL) approach to interdisciplinary collaboration.

\title{
Review of Related Literature
}

\author{
Interdisciplinary Collaboration
}

According to Snow, Salmon, and Young (2010), "universities are typically structured in discipline-separate silos" (p. 160) which encourages discipline-specific research. Many scholarly articles posit that, while there is a place in the academy for disciplinary research (Nissani, 1997), many benefits result from projects that bring individuals from a variety of disciplines to work together using a cross-disciplinary approach. There are three major models of disciplines working together to address a common problem. Multidisciplinary research is when "researchers work in parallel or sequentially from [a] disciplinary-specific base" (Rosenfield, 1992, p. 1351). Interdisciplinary research is when "researchers work jointly but still from [a] disciplinary-specific basis" (Rosenfield, 1992, p. 1351). Transdisciplinary research is when "researchers work jointly using shared conceptual frameworks drawing together disciplinary-specific theories, concepts, and approaches" (Rosenfield, 1992, p. 1351). The project reported in this paper adopted an interdisciplinary approach. The literature suggests that interdisciplinary teams are effective when they seek to address complex real-world problems (Beers et al., 2006; Choi \& Pak, 2006; Fischer \& Otswald, 2005; Massey, Alpass, Flett, Lewis, Morriss, \& Sligo, 2006), incorporate different perspectives (Choi \& Pak, 2006), benefit from the social nature of research (Wasser \& Bresler, 1996), enhance their creative and innovative capacity (Cummings \& Kiesler, 2005; Levine \& Moreland, 2004; Nissani, 1997), and enrich the training of students (Bruusgaard et al., 2010).

For interdisciplinary teams to be most effective, they should strive to avoid the pitfalls of interdisciplinary collaboration: distance between team members (Stokols et al., 2005); communication issues arising from unclear objectives and processes (Beers et al., 2006; Fischer \& Otswald, 2005); ethical issues and complexities stemming from authorship decisions (Fine \& Kurdek, 1993); and failure to allow all members to maintain their autonomy and contribute meaningfully (Bruusgaard et al., 2010; Kennedy, 1995).

Further, teams should strive to incorporate effective practices. The literature suggests that interdisciplinary projects are more successful when they incorporate regular face-to-face interactions (Stokols et al., 2005), develop a shared understanding of the problems they are attempting to address and their method of tackling problems (Fischer \& Otswald, 2005), and utilize strategies to achieve effective team dynamics, such as establishing trusting, non-hierarchical, and open environments (Bruusgaard et al., 2010).

\section{Community Service-Learning}


In addition, the project incorporated elements of CSL programs. Although there is no standard definition of CSL easily identified in the literature (Cameron, 2010), there are a number of common elements described in practice materials. Typically, CSL programs involve a "collaboration between academic institutions and community organizations" (Cameron, 2010, p. 6) and is usually a "course-based, credit-bearing educational experience" (Gemmel \& Clayton, 2009 , p. 10) wherein a post-secondary student is placed in a community organization. The process, experience, learning, and outcomes of the collaboration are usually critically reflected upon by students (CASL, n.d.; Gemmel \& Clayton, 2009).

The literature also elaborates upon a number of benefits that often result from CSL programs for participating students, community organizations, and post-secondary institutions. For example, students are reported to benefit from experiential learning, critical self-reflection, the development of transferable skills, the opportunity to put theory into practice, and the opportunity to use their post-secondary knowledge to benefit communities (Gemmel \& Clayton, 2009). Thus, the students involved in CSL programs benefit from the "integration of learning with service" (Gemmel \& Clayton, 2009, p. 9). Community organizations benefit as students provide services free of financial cost (Tryon \& Stoecker, 2008), complete necessary projects (Tryon \& Stoecker, 2008), and contribute new ideas and disciplinary expertise (Gemmel \& Clayton, 2009). Finally, post-secondary institutions and instructors benefit because CSL programs can be utilized by any discipline (Gemmel \& Clayton, 2009), build "intentional learning activities" for students (CASL, n.d, para. 1), "fulfill academic learning goals" (Gemmel \& Clayton, 2009, p. 10), and develop partnerships.

While CSL programs are beneficial for stakeholders, they also have drawbacks. First, the outputs produced by students might not address the organization's needs (Gemmel \& Clayton, 2009, p. 20). Second, relationship-building takes time, so when students are placed in an organization for a short period, it can be difficult to form meaningful relationships (Tryon \& Stoecker, 2008). Third, it can be challenging for organizations to manage and evaluate student work (Tryon \& Stoecker, 2008). Fourth, students may not have the cultural competency (Tryon \& Stoecker, 2008) necessary to work within a particular organization. If this is the case, students may require a significant amount of training.

Considering the drawbacks, the literature illuminates ways to maximize CSL programs. Tryon and Stoecker (2008) caution that "it is imperative that there be clear and realistic shared goals, strong relationships with faculty, carefully focused and simple projects requiring little training, and committed students" (p. 52) as well as strong communication between faculty, students, and community partners to generate success (Tryon \& Stoecker, 2008). To enhance communication, the values and work habits of the students and the organization must be compatible or aligned (Tryon \& Stoecker, 2008). Finally, students should be given the opportunity to reflect on what they learned (Gemmel $\&$ Clayton, 2009).

\section{The App Development Project}

\section{Initiation of the Collaboration}

The team had twelve members - three professors, one research manager, one doctoral student, an undergraduate student, and six computing science students. As it was difficult to find time for all members of the team to meet on a weekly basis, the team created two working groups. The content working group ("CWG") (members with non-computing science backgrounds) was in charge of creating the app content, communicating content needs, beta-testing the prototype, and providing feedback on the app. The software working group (“SWG”) (members with computing science backgrounds) was in charge of building the software infrastructure, raising questions, surfacing challenges, and finding solutions.

To establish effective practices and to avoid pitfalls common to interdisciplinary collaboration and CSL, an undergraduate student was chosen as the liaison between the groups. The liaison was selected to enhance interpersonal dynamics and communication, promote clarity, facilitate face-to-face interaction, promote a non-hierarchical environment, and support and enhance interdisciplinary communication. The liaison role included gathering the project's 
specifications and technical requirements, communicating the specifications and requirements, and being available when either group had questions and suggestions.

\section{Collaboration Details}

In preparation for the collaboration, the liaison collated the information that the SWG would need including details about the project's background, objectives, target users, stakeholders, usability, functional requirements according to the user types, and quality requirements (e.g., privacy). Once gathered, the information was compiled into a specifications document which served as a frame of reference.

The collaboration kicked off at the beginning of an academic semester. The liaison led the first meeting with both working groups present and introduced the project specifications document. In this meeting, being cognizant of the possibility that there might be differences in disciplinary language to overcome, the liaison strove to avoid jargon and avoid making assumptions. All team members quickly realized that communication would be challenging. This challenge was a growth opportunity for the computing science students in particular as application developers often need skills to overcome communication challenges with clients and partners who neither possess the same technical expertise nor speak the same technical language as the software developers. In response to this challenge, the SWG was encouraged to ask questions to ensure clarity. To further enhance clarity and to build understanding, the liaison met weekly with each group and limited online communication to short, clear questions and answers. Major project changes were only discussed in-person. During weekly group meetings, the liaison took notes and documented each task, the member responsible for the task, and the deadline for completion of the task. The liaison then relayed the information from one group to the other. This process allowed each working group to perform their assigned tasks while allowing for detailed communication amongst team members.

Over the course of the semester, the project morphed in ways not originally anticipated. By the time the project was completed, the SWG had used their technical knowledge and training to develop an app prototype that provided greater functionality than envisaged. During development, the SWG raised questions the CWG had not considered. Thus, the SWG's suggestions improved the end product. At the conclusion of the semester, after beta-testing and refinement, a successful product was developed, a user manual was created, and the students presented detailed information about the collaboration to their professor and peers. At the end of the collaboration, the students reflected on their learning by completing a short questionnaire.

\section{Results}

From the CWG's perspective, three major benefits flowed from the collaboration. First, the CWG was able to benefit from the expertise of the computing science students; the students not only created a well-functioning app, but they also improved the anticipated product. Second, the app and database were developed and provided free of financial cost. If the CWG had paid a software developer to complete the work, it would have significantly impacted the project's budget. Third, the collaboration enriched the training of the undergraduate student member who liaised between the groups. This student learned how to be a better information technology client - learning about the value of user stories, specifications, and technical requirement gathering. Additionally, the experience sharpened the student's understanding of the challenge of collaborating across disciplines, including the time involved and the critical need for ongoing, in-person, and open communication. The experience also improved the liaison's understanding of the challenge of providing sufficient initial project details in an interdisciplinary setting wherein all the questions that collaborators from other disciplines can conceive of are not known, anticipated, or understood. Thus, the interdisciplinary approach resulted in the CWG gaining expertise at the best cost to achieve the desired outcome while providing a valuable learning opportunity for their undergraduate student.

The project was of value to the SWG. The value of the collaboration to the SWG was ascertained using a survey. The survey focused on the students' evaluation of the effectiveness of the collaboration and its impact on their 
learning and development. A few themes emerged from their responses. First, the students relished the opportunity to tackle a real problem. In their responses, the students indicated that their school projects are often theoretical and does not often end up being used. As one student explained, "Many [computing science] projects are not real world, so getting to create a project that will be used was very valuable. Working with the... [CWG] and creating the tools they envisioned was a useful learning experience". Second, the students appreciated the opportunity to gain experience communicating with others from different disciplinary backgrounds. One student indicated that "the aspects of the project [that were] most beneficial to me [were] having an actual client and engaging in discussions and meetings with them". Third, the students communicated that the project provided the ability to advance their technical software development skills and work cohesively as a team. One student stated, "I did grow my knowledge of android app development, but I really felt this project was a fun collaboration to work on that went surprisingly well". Another student expressed that he "learned that...teamwork is really [important]...it gave me some skill [in] communicating with clients". From an educational standpoint, the collaboration provided the opportunity to advance career-related skills and tackle a real project and communication challenges. Third, the academic institution benefited by providing students with an experiential learning opportunity that actioned course learning objectives. In the course, the students attended lectures about app development which they put into action. The opportunity was enhanced by requiring students to overcome communication challenges, collaborate with others, and engage in problem-solving in a manner expected in the workforce.

While the project was beneficial, the team experienced challenges. First, there was not enough face-to-face communication. The insufficient direct contact was a result of time constraints and scheduling difficulties. While the lack of in-person time was explainable, it limited the creation of meaningful relationships between the working groups (Tryon \& Stoecker, 2008). Second, the project needed to be completed within a semester and built on the parameters outlined in the software course. As a result, the app had to be for android devices only. Overall, the challenges paled in comparison to the benefits.

\section{Discussion}

The project incorporated a number of the typical elements of interdisciplinary collaboration. The collaboration was interdisciplinary by integrating the perspectives of individuals from many disciplines (Choi \& Pak, 2006; Rosenfield, 1992) including human ecology, gerontology, material culture, design, education, and computing science. By working together, the team addressed a real-world problem (Choi \& Pak, 2006; Fischer \& Otswald, 2005) and team members benefited from the perspectives of others from different disciplines to create an app that drew on their combined knowledge and skills.

The collaboration also involved some of the components typical of CSL programs. For instance, the project involved a partnership between the original research team and a professor whose students benefited from a hands-on learning opportunity where they put theory into practice (Gemmel \& Clayton, 2009). Working this way enabled the original team to utilize the expertise of the computing science students and enabled the computing science students to offer new ideas which influenced the project's end result - ideas that built on the knowledge and skills acquired by students in their academic studies. As well, the collaboration resulted in the students earning post-secondary course credit while creating a useable app.

The collaboration model used also differed from CSL programs in a few ways. First, the undergraduate student who was part of the original team served as the liaison between the CWG and SWG, whereas a professor usually coordinates the collaboration in a CSL program. Second, the collaboration model did not incorporate as much intentional critical reflection (Gemmel \& Clayton, 2009) as is often included in CSL programs. Third, the collaboration between the CWG and the SWG was a within-institution collaboration. This is a deviation from CSL as, according to Cameron (2010), CSL involves "collaboration between academic institutions and community organizations" (p. 6). However, this deviation from the typical CSL program model strengthened the project by fostering interdisciplinary and interdepartmental collaboration. 


\section{Applicability of the Collaboration Model}

The within-institution, interdisciplinary, CSL-like model used by the full team is a model other teams should consider replicating. The model is an avenue for students, faculty, and staff to learn from each other and contribute to each other's success. For students, in addition to other advantages, the model allows them to interact with professors, students, and staff from different faculties and departments. In doing so, the students are exposed to the language, theories, and knowledge of other disciplines. To overcome disciplinary language barriers, the students cultivate their communication skills. As a result, they are doing even more than putting their academic knowledge into practice. For professors, the model enriches the learning environment and academic objectives. Further, the students' ability to use their knowledge to achieve team objectives demonstrates the success of the university's teaching, learning, and innovation goals.

\section{Future Use of the Collaboration Model}

This reflective case study demonstrates that while the model was highly successful, a few changes would maximize its benefits. First, while the app development collaboration commenced with a discussion of the project specifications document, any future collaboration should commence prior to the project specifications being developed. This earlier kick off is expected to result in more fulsome project specifications based on the full team's exploration of the project's intended parameters and outcomes. Second, in the initial drafting of the project goals, there were no documented goals concerning student-related outcomes. In future, training and growth for all students involved in the collaboration should be a recognized and documented outcome. Third, the liaison did not appreciate the time commitment required of this critical role. In employing the model, if there is a liaison role, the team should ensure the liaison is cognizant of the considerable amount of time needed to determine the process for working together and ensure understanding amongst project members from different disciplines and with varying levels of academic achievement. Fourth, the project would have benefited from more frequent full team meetings. Frequently scheduled in-person team meetings are recommended to enhance the full exploration of questions, challenges, opportunities, and solutions. In sum, communication is key.

\section{Conclusion}

In the context of research and project development, a collaboration model incorporating elements of within-institution interdisciplinary CSL-like programs is worth exploring. It is an example of a set of productive relationships that advance the training of students (Bruusgaard et al., 2010) and highlight the social nature of the research process (Wasser \& Bresler, 1996), the importance of the communication process, and the value of allowing all collaborators to meaningfully contribute regardless of their stage of career (Kennedy, 1995; Bruusgaard et al., 2010).

\section{References}

AGE-WELL. (n.d.). AGE-WELL graduate student and postdoctoral awards in technology and aging (2017). Retrieved from http://agewell-nce.ca/training/graduate-student-and-postdoctoral-award.

Beers, P., Boshuizen, H., Kirschner, P., Gijselaers, W. (2006). Common ground, complex problems and decision making. Group Decision and Negotiation, 15(6), 529-556. Retrieved from http://dx.doi.org/10.1007/s10726-006$\underline{9030-1}$. 
Bruusgaard, E., Pinto, P., Swindle, J., \& Yoshino, S. (2010). “Are we all on the same page?”: The challenges and charms of collaboration on a journey through interdisciplinarity. Graduate Journal of Social Science, 7(1), 39-58.

Cameson, S. (2010). Getting wisdom: The transformative power of community service-learning. Retrieved from https://mcconnellfoundation.ca/wp-content/uploads/2017/07/Getting-Wisdom-Web.pdf.

Canadian Alliance for Community Service-Learning. (n.d.). What is community service-learning? Retrieved from http://www.communityservicelearning.ca/en/welcome what is.htm.

Choi, B., \& Pak, A. (2006). Multidisciplinarity, interdisciplinarity and transdisciplinarity in health research, services, education and policy: 1. Definitions, objectives, and evidence of effectiveness. Clinical and Investigative Medicine, 29(6), 351-364.

Cummings, J., \& Kiesler, S. (2005). Collaborative research across disciplinary and organizational boundaries. Social Studies of Science, 35(5), 703-722. Retrieved from http://www.dx.doi.org/10.1177/0306312705055535.

Fine, M., \& Kurdek, L. (1993). Reflections on determining authorship credit and authorship order on faculty-student collaborations. The American Psychological Association, 48(11), 1141-1147. Retrieved from http://dx.doi.org/10.1037/0003-066X.48.11.1141.

Fischer, G., \& Otswald, J. (2005). Knowledge communication in design communities. In R. Bromme, F. Hesse, \& H. Spada (Eds.), Barriers and Biases in Computer-Mediated Knowledge Communication (pp. 213-242). Retrieved from https://link.springer.com/chapter/10.1007/0-387-24319-4_10.

Gemmel, L., \& Clayton, P. (2009). A comprehensive framework for community service-learning in Canada. Canadian Alliance for Community Service Learning. Retrieved from http://www.communityservicelearning.ca/en/documents/AComprehensiveFrameworkforCSL.pdf.

Keating, N. \& Eales, J. (2017). Social consequences of family care of adults: A scoping review. International Journal of Care and Caring, 1(2), 153-173.

Keating, N., Fast, J., Lero, D. S., Lucas, S., \& Eales, J. (2014). A taxonomy of the economic costs of family care to adults. Journal of the Economics of Ageing, 3, 11-20.

Kennedy, E. (1995). In pursuit of connections: Reflections on collaborative work. American Anthropologist, 97(1), 26-33. Retrieved from http://www.jstor.org/stable/682376.

Levine, J., \& Moreland, R. (2004). Collaboration: The social context of theory development. Personality and Social Psychology Review, 8(2), 164-172. Retrieved from http://jour-

nals.sagepub.com/doi/abs/10.1207/s15327957pspr0802 10.

Massey, C., Alpass, F., Flett, R., Lewis, K., Morriss, S., \& Sligo, F. (2006). Crossing fields: The case of a multidisciplinary research team. Quantitative Research, 6(2), 131-149. Retrieved from http://dx.doi.org/10.1177/1468794106062706.

Nissani, M. (1997). Ten cheers for interdisciplinarity: The case for interdisciplinary knowledge and research. Social Science Journal, 34(2), 201-217. Retrieved from https://doi.org/10.1016/S0362-3319(97)90051-3.

Sinha, M. (2013). Spotlight on Canadians: Results from the General Social Survey, Portrait of caregivers, 2012. (Statistics Canada Catalogue no. 89-652-X - No. 001). Ottawa ON: Ministry of Industry. Retrieved from http://www.statcan.gc.ca/pub/89-652-x/89-652-x2013001-eng.pdf. 
Rosenfield, P. (1992). The potential of transdisciplinary research for sustaining and extending linkages between the health and social sciences. Social Science \& Medicine, 35(11), 1343-1357.

Snow, E., Salmon, A., \& Young, R. (2010). Teaching transdisciplinarity in a discipline-centred world. Collected Essays on Learning and Teaching, 3, 159-165. Retrieved from https://files.eric.ed.gov/fulltext/EJ1058336.pdf.

Stokols, D., Harvey, R., Gress, J., Fuqua, J., \& Phillips, K. (2005). In vivo studies of transdisciplinary collaboration: Lessons learned and implications for active living research. American Journal of Preventative Medicine, 28(2), 202213. Retrieved from http://dx.doi.org/10.1016/j.amepre.2004.10.016.

Tryon, E., \& Stoecker, R. (2008). The unheard voices: Community organizations and service-learning. Journal of Higher Education Outreach and Engagement, 12(3), 47-59. Retrieved from http://openjournals.libs.uga.edu/index.php/jheoe/article/view/99/87.

Turcotte, M. (2013). Insights on Canadian society, family caregiving: What are the consequences? (Statistics Canada Catalogue no. 75-006-X). Ottawa ON: Ministry of Industry. Retrieved from http://www.statcan.gc.ca/pub/75006-X/2013001/article/11858-eng.pdf.

Wasser, J., \& Bresler, L. (1996). Working in the interpretive zone: Conceptualizing collaboration in qualitative research. American Educational Research Association, 25(5), 5-15. Retrieved from http://www.jstor.org/stable/1176204. 